\title{
Estilos de vida de los estudiantes de obstetricia en una Universidad del Norte del Perú
}

\section{Lifestyles of obstetric students at a University in the North of Peru}

Jhon Edwin Ypanaque Ancajima $\mathbb{1}^{1}$, Dario Paquiyauri Dioses $\mathbb{1}^{1}$, José Luis Saly Rosas Solano $\mathbb{1}^{1}$

1 Universidad Nacional de Tumbes, Tumbes - Perú.

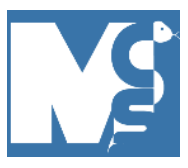

Recibido: 09/09/2020

Revisado: 10/09/2020

Aceptado: 17/09/2020

\section{Autor correspondiente}

\section{Jhon Ypanaque}

Universidad Nacional de Tumbes

Tumbes - Perú

ihon.unt@gmail.com

\section{Conflictos de interés}

Los autores declaran no poseer conflictos de interés.

\section{Fuente de financiación}

Los autores no recibieron apoyo financiero para la investigación, autoría y/o publicación de este artículo.

Este artículo es publicado bajo una licencia de Creative Commons Reconocimiento 4.0 Internacional.

\section{Estimado editor:}

Respecto al artículo "Síndrome de Burnout y dependencia al alcohol en estudiantes de Medicina" (1), precisarle algunos resultados de nuestro estudio, donde se entrevistaron a 128 estudiantes de obstetricia de la Universidad Nacional de Tumbes del norte del Perú. Los resultados describen las causas de estrés y consumo de sustancias toxicas se ven en la Tabla 1.

TABLA 1. CARACTERÍSTICAS DE LA MUESTRA $(n=128)$.

\begin{tabular}{lcc}
\hline \multicolumn{1}{c}{ Presencia de síntomas de estrés } & Frecuencia & $(\%)$ \\
\hline Sí presenta síntomas de estrés & 89 & 70 \\
No presenta síntomas de estrés & 39 & 30 \\
\multicolumn{1}{c}{ Estrés según tipo de situación } & Frecuencia & $(\%)$ \\
Exámenes parciales & 15 & 12 \\
Sobrecarga académica & 40 & 31 \\
Problemas Familiares & 12 & 9 \\
Problemas con mi pareja & 05 & 4 \\
Problemas económicos & 17 & 13 \\
Ninguna & 39 & 30 \\
\hline
\end{tabular}

La etapa de formación universitaria se considera como condicionante para la generación de estrés, situación que puede sobrecargar a los estudiantes por las excesivas horas académicas, que, a pesar del uso de recursos de afrontamiento psicosocial, pueden originar trastornos mentales, somáticos y hasta desadaptación social (2).

Adicional a esto se resalta que, en el periodo universitario se aprende conductas que muchas veces perduran hasta la adultez, por tal motivo es clave el desarrollo de actividades que promuevan y prevengan diversos problemas en salud, ya que los estilos de vida en esta etapa influirán de forma directa en el desarrollo psíquico, físico y mental (3).

Al abordar la dimensión sustancias tóxicas, cabe citar que su consumo (alcohol, tabaco y drogas ilegales), está referido cuando se ingiere, aplica y absorbe dichas sustancias, las cuales degeneran en el centro nervioso central y el comportamiento (4). Es en las universidades, donde se presenta el riesgo de ingesta de bebidas alcohólicas y sustancias psicoactivas, esto debido a la diversidad factores que influyen en el consumo de sustancias psicoactivas, como 
son: La baja autoestima, el estrés académico, disponibilidad de estas sustancias en el contexto y la falta de programas preventivos o de ayuda al estudiante (5).

El estrés como proceso puede llegar a tener consecuencias a corto y largo plazo, académicamente afecta la parte emocional, el estado físico y las relaciones interpersonales, siendo experimentadas de distinta manera por cada individuo (5).

\section{REFERENCIAS}

1. González I, Alfonzo A, Aranda J, Cámeron S, Chávez D, Duré N, et al. Síndrome de Burnout y dependencia al alcohol en estudiantes de Medicina. Med Clín Soc. 2020;4(2):52-9.

2. Monzón IMM. Estrés académico en estudiantes universitarios. Apuntes de psicología. 2007;25(1):87-99.

3. De Luna-Bertos E. Hábitos de vida saludable en la población universitaria. Nutrición hospitalaria. 2015;(5):1910-9. https://dx.doi.org/10.3305/nh.2015.31.5.8608

4. Varela MT, Duarte C, Salazar IC, Lema LF, Tamayo JA. Actividad física y sedentarismo en jóvenes universitarios de Colombia: prácticas, motivos y recursos para realizarlas. Colombia Médica. 2011;42(3):269-77.

5. Claros JAV, Álvarez CV, Cuellar CS, Mora MLA. Actividad física: estrategia de promoción de la salud. Hacia la Promoción de la Salud. 2011;16(1):202-18. 